\title{
Cardio-ankle vascular index (CAVI) as an indicator of arterial stiffness
}

This article was published in the following Dove Press journal:

Integrated Blood Pressure Control

29 April 2013

Number of times this article has been viewed

\section{Cheuk-Kwan Sun}

Department of Emergency Medicine, Department of Medical Education, E-Da Hospital, I-Shou University, Kaohsiung, Taiwan
Correspondence: Cheuk-Kwan Sun Department of Emergency Medicine, E-Da Hospital, I-Shou University, No I, Yida Road, Jiaosu Village, Yanchao District, Kaohsiung City 82445, Taiwan

$\mathrm{Tel}+8867615001 \mathrm{I}$ ext 1007

Fax +886 76150915

Email lawrence.c.k.sun@gmail.com
Abstract: Arterial stiffness has been identified as an independent predictor of prognostic outcomes for patients with cardiovascular disease. Although measurement of pulse wave velocity has been a widely accepted noninvasive approach to the assessment of arterial stiffness, its accuracy is hampered by changes in blood pressure. Taking the exponential relation between intravascular pressure and arterial diameter into consideration, a stiffness parameter can be obtained by plotting the natural logarithm of systolic-diastolic pressure ratio against the arterial wall extensibility. Cardio-ankle vascular index (CAVI), which is calculated based on the stiffness parameter thus obtained, is theoretically independent of changes in blood pressure. With this distinct advantage, CAVI has been widely applied clinically to assess arterial stiffness in subjects with known cardiovascular diseases including those with diagnosed atherosclerosis, coronary heart disease, and stroke as well as those at risk, including those with hypertension, diabetes, the elderly, and the obese. Because of its enhanced sensitivity, not only has the index been used to discern subtle changes in the disease process, it has also been utilized in studying normal individuals to assess their potential risks of developing cardiovascular diseases. The primary aims of assessing arterial stiffness using CAVI are not only to aid in early detection of arteriosclerosis to allow timely treatment and change in lifestyle, but also to quantitatively evaluate the progression of disease and the effectiveness of treatment. Despite its merit of being unaffected by blood pressure, discretion in data interpretation is suggested because an elevated CAVI represents not just vascular stiffness caused by pathological changes in the arterial wall, but can also be attributed to an increased vascular tone brought about by smooth muscle contraction. Moreover, certain patient populations, such as those with an ankle-brachial index $<0.9$, may give falsely low CAVI and are suggested to be excluded from study.

Keywords: cardio-ankle vascular index, stiffness parameter, cardiovascular disease, atherosclerosis, arteriosclerosis, pulse wave velocity

\section{Background: history and development Arterial stiffness as an indicator of systemic diseases}

"Stiffness" of the artery depends on its intrinsic elasticity. One commonly used indicator is pulse wave velocity (PWV) which increases with stiffness of the arterial wall. Although the major contributor to arterial stiffness is believed to be atherosclerosis, it has been shown that there is no notably significant correlation between PWV and the established risk factors for atherosclerosis with the exception of age and blood pressure. ${ }^{1}$ Besides, PWV does not reflect early pathological changes of atherosclerosis until at its advanced stage when calcification develops in the atherosclerotic plaque. ${ }^{2}$ The impact of age on the development of arterial stiffness, therefore, has aroused 
much interest. ${ }^{3}$ Indeed, age-related increase in arterial stiffness has been shown to involve mainly the major arteries rather than the peripheral ones. ${ }^{4}$ Interestingly, it has been found that the pathogenic mechanisms that contribute to arterial stiffness are different for atherosclerosis and aging. While the former affects mainly the arterial intima resulting in an increase in intima-media thickness and the formation of atherosclerotic plaques, the latter causes "medial degeneration" that involves increase in collagen and calcium deposits as well as fragmentation of elastin lamellae in the medial layer as a result of upregulation of proteolytic enzymes and possible repetitive cyclic stress on the arterial wall over a life span. ${ }^{5,6}$ Another chronic disease, diabetes mellitus, has also been shown to enhance the production of advanced glycation end-products (AGEs) that causes collagen crosslinking in the arterial medial layer which has been shown to be a significant contributor to arterial stiffness. ${ }^{7}$

\section{Arterial stiffness reflected in increased pulse wave velocity as a parameter for assessing vascular health}

Arterial stiffness refers to the reduced distensibility and contractility of the arterial wall in response to pressure changes. The distensibility, which is defined as the relative change in volume in response to a change in blood pressure, is the ability of the artery to expand during systole. ${ }^{8} \mathrm{PWV}$, on the other hand, is the velocity of propagation of the pressure wave along the arterial tree and is calculated by dividing the distance between two set points by the transit time needed for the wave to cover this distance. ${ }^{9} \mathrm{PWV}$ is increased by a reduction in the intrinsic elasticity of the arterial wall (ie, "stiffer" arteries) as in arteriosclerosis. Indeed, arterial stiffness, as measured by carotid-femoral PWV, has been reported to be an independent predictor of cardiovascular mortality and morbidity in patients with hypertension, type 2 diabetes, end-stage renal disease, and in the elderly. ${ }^{10}$ Moreover, because of its noninvasiveness and high reproducibility of results, ${ }^{11}$ it has been widely accepted as a clinical tool for diagnosing hypertension and following treatment outcomes. ${ }^{12}$

\section{Current methods of pulse wave velocity measurement and their limitations}

By definition, PWV is the distance traveled by the wave divided by the time for the wave to cover that distance. However, this is the case only in a system with zero wave reflections. Actually, the transmission of the arterial pressure pulse does not reflect a true PWV because the former is a sum of vectors of the incident and reflected waves. To minimize the error in the calculation of the forward pulse velocity, one of the measuring points is typically chosen near the foot which is the lowest point of the flow wave relatively free of arterial wave reflection..$^{13}$ An alternate approach to measuring PWV takes advantage of the minimal interference with the incident pressure wave by the reflected wave during late diastole and early systole. ${ }^{14}$ Based on the assumption, PWV can be determined by dividing the distance between two sites with the transit time between the foot points of an arterial pressure waveform captured at the two points of reference. Nevertheless, precise determination of the location of the foot points can be problematic. ${ }^{15}$ Moreover, the original PWV involved velocity measurement between the carotid and femoral artery. However, acquisition of an accurate waveform with the procedure is somewhat complicated. ${ }^{16}$ Therefore, instead of capturing the pressure wave, the use of Doppler ultrasound for measuring the flow wave has been suggested. ${ }^{17}$ On the other hand, brachial-ankle pulse wave velocity (baPWV), which is a simplified approach with the use of air pressure and a volume plethysmograph that measures the PWV of the brachial artery (ba) and the ankle, was introduced. ${ }^{16}$

One of the innate limitations of using PWV in the assessment of vascular pathologies is the fact that the measured or "functional" stiffness as reflected in the magnitude of PWV depends on the pressure of blood exerted on the arterial wall. Indeed, it has been demonstrated that the measured stiffness increases with a rise in loading pressure without any structural change. ${ }^{18}$ For instance, baPWV is affected by blood pressure which is not compensated for during measurement. ${ }^{19,20}$ In addition, since the pulse pressure is measured by air pressure, any stimulus that creates pressure on an artery may affect the results. ${ }^{16}$ Furthermore, albeit not substantial, PWV is lower during inspiration than expiration which causes a slight elevation in blood pressure. ${ }^{21}$

\section{Introduction of the cardio-ankle vascular index (CAVI) and its features}

Taking the above issues into consideration, a CAVI, which is a stiffness and arteriosclerosis indicator of thoracic, abdominal, common iliac, femoral, and tibial arteries independent of arterial blood pressure, was proposed. ${ }^{16,22}$ Basically, CAVI is obtained by recording the distance 
from the level of the aortic valve (ie, brachial level) to the measuring point (ie, the ankle) and the time delay between the closing of the aortic valve to the detected change in arterial pressure wave at the set point. ${ }^{16}$ Information for CAVI computation, including PWV, systolic and diastolic blood pressure as well as arterial pulse waveforms, can then be acquired through the electrocardiogram, cardiac phonogram, and the pressure cuffs on the testing subject at the reference points.

In comparison to baPWV, CAVI has two distinctive features. First, CAVI changes over a short period of time in response to alterations in circulatory condition. Second, CAVI reflects the state of smooth muscle contraction rather than changes in blood pressure. ${ }^{23}$ CAVI has also been reported to represent both "functional" and "organic" stiffness. ${ }^{24}$ The former represents the state of smooth muscle contraction that is subjected to changes in sympathetic tone and also pharmacological influence, whereas the latter signifies the physical properties such as sclerotic change of the arterial wall. While the administration of a selective beta 1-blocker, which decreases the contraction of cardiac muscle and blood pressure without affecting the vascular tone of arterial wall, led to a reduction in baPWV in human subjects, the CAVI stayed unchanged. On the other hand, infusion of an alpha-1 adrenergic receptor blocker, which decreases blood pressure through a relaxation of the smooth muscle of peripheral arteries, caused a diminished CAVI score. ${ }^{25}$ The findings, therefore, highlight the influence of vascular tone on the magnitude of CAVI in spite of its blood pressure independence.

\section{CAVI: theories and computation}

In 1926, Otto Frank ${ }^{26}$ defined the propagating velocity of the arterial pressure pulse, $\Delta \mathrm{P}$, as "characteristic pulse wave velocity (PWVc)" ie,

$$
P W V c=\sqrt{ }(K / \rho)
$$

where $\mathrm{K}$ is the elastic modulus of luminal volume change per unit length of artery and $\rho$ is the density of blood.

On the other hand, arterial stiffness can be defined by its distensibility, or preferably "compressibility", ${ }^{27}$ which is the relative change in volume in response to a change in blood pressure. That is: Compressibility $=(\Delta \mathrm{V} / \mathrm{V}) / \Delta \mathrm{P}$, where $\Delta \mathrm{V}=$ change in volume; $\mathrm{V}=$ original volume; $\Delta \mathrm{P}=$ change in pressure.
Since the elastic modulus, $\mathrm{K}$, is defined as the ratio of stress (ie, the pulse pressure) to strain (ie, the fractional volume change) per unit length of artery, it is the inverse of compressibility. That is:

$$
\mathrm{K}=\Delta \mathrm{P} /(\Delta \mathrm{V} / \mathrm{V})
$$

Since $V=\pi R^{2}$ (where $R$ : luminal radius), then $d V=2 \pi R d R$, and if $\Delta \mathrm{V}$ (ie, luminal volume change per unit length of artery) is small, $\mathrm{dV} / \mathrm{V}=\Delta \mathrm{V} / \mathrm{V}=2 \Delta \mathrm{R} / \mathrm{R}=2 \Delta \mathrm{D} / \mathrm{D}$ (where $\mathrm{D}$ : luminal diameter), then equation 2 may be written as:

$$
\mathrm{K}=\Delta \mathrm{P} /(2 \Delta \mathrm{D} / \mathrm{D})
$$

In 1961, Bergel $^{18}$ proposed that the hoop tension, $\mathrm{T}$, in the artery wall of thickness, h, was related to the luminal pressure, $\mathrm{P}$, by the equation:

$$
\mathrm{P}=\mathrm{Th} / \mathrm{R}, \text { ie, } \mathrm{T}=\mathrm{PR} / \mathrm{h} \text {. }
$$

Suppose that the changes in luminal radius, $\mathrm{R}$, and arterial wall thickness, $h$, are negligible, then the relation between a small change in luminal pressure, $\Delta \mathrm{P}$, and the corresponding change in stress, $\Delta \mathrm{T}$, can be given by $\Delta \mathrm{T}=\Delta \mathrm{PR} / \mathrm{h}$. The circumferential strain caused by $\Delta \mathrm{T}$ will be $[2 \pi(\mathrm{R}+\Delta \mathrm{R})-$ $2 \pi \mathrm{R}] / 2 \pi \mathrm{R}$, giving $\Delta \mathrm{R} / \mathrm{R}$.

Therefore, Einc, the static incremental Young's modulus, which is stress/strain for the material of the arterial wall, can be defined as:

$$
\text { Einc }=(\Delta P \cdot R / h) /(\Delta R / R)
$$

Hence, Einc, the static incremental Young's modulus, can be rewritten as:

$$
\text { Einc }=\Delta \mathrm{P} \cdot \mathrm{D}^{2} / 2 \mathrm{~h} \Delta \mathrm{D} \text {. }
$$

The equation was based on the assumption of blood flow inside an infinitely long, thin-walled elastic tube with an incompressible fluid and with the elasticity of the tube wall considered to be isotropic in the absence of any pressure reflections from the periphery.

Combining (1), (3), and (5) gives:

$$
P W V c=\sqrt{ }\left(E_{i n c} \cdot h / D \cdot \rho\right)
$$

The equation was commonly referred to as the MoensKorteweg equation. ${ }^{28}$ 
Alternatively, substituting (2) into (5) gives: PWVc = $\sqrt{ } \Delta \mathrm{P} \cdot \mathrm{D} /(2 \rho \cdot \Delta \mathrm{D})$, which can be rewritten as:

$$
\mathrm{D} / \Delta \mathrm{D}=(2 \rho / \Delta \mathrm{P}) \cdot \mathrm{PWV}^{2},
$$

where PWV: pulse wave velocity; $\Delta \mathrm{P}$ : pulse pressure; $\rho$ : density of blood; D: luminal diameter; $\Delta \mathrm{D}$ : change in luminal diameter.

Equation (7) thus derived provides a theoretical model that links the PWV, compressibility, pulse pressure, and blood density, it was first proposed by Bramwell and Hill..$^{29}$ Although the Bramwell and Hill ${ }^{29}$ equation was based on the MoensKorteweg model, the former is believed to be more general because it does not assume thin-walled and homogeneous elastic arteries, as in the Moens-Korteweg model. ${ }^{9}$

On the other hand, CAVI is calculated based on a stiffness parameter, $\beta$, which was first proposed by Hayahi et al in 1975 to assess the local stiffness of a blood vessel according to the change in vascular diameter in response to arterial pressure variance. ${ }^{30}$ To fit into clinical practice, this blood pressure-independent parameter was later defined by Kawasaki et $\mathrm{al}^{31}$ as:

$$
\beta=\operatorname{In}\left(\mathrm{P}_{\mathrm{s}} / \mathrm{P}_{\mathrm{d}}\right) \cdot(\mathrm{D} / \Delta \mathrm{D})
$$

Using an echo phase tracing system, the proportional change in luminal diameter (ie, $\Delta \mathrm{D} / \mathrm{D}$ ) can be obtained. Provided that an exponential relation exists between intravascular pressure and arterial diameter under stable physiological condition theoretically because of the transfer of stress from the stretchable elastin to the stiff collagen fibers in the arterial wall as blood pressure increases (Figure 1A), ${ }^{32}$ plotting the natural logarithm of systolic-diastolic pressure ratio $\left(\mathrm{In}_{\mathrm{s}} / \mathrm{P}_{\mathrm{d}}\right)$ against the arterial wall extensibility $(\Delta \mathrm{D} / \mathrm{D})$ would give a linear relation (Figure 1B). Therefore, the stiffness parameter

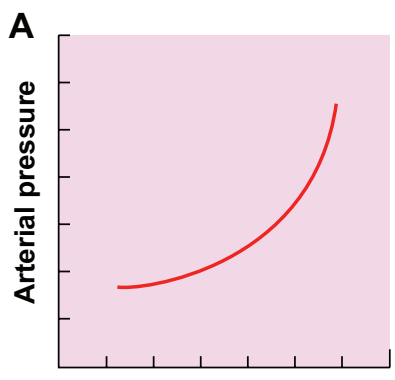

Arterial diameter

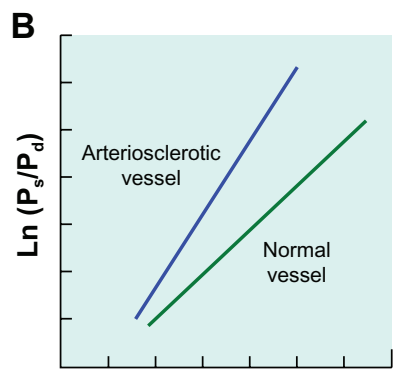

Arterial distensibility
Figure I (A) An exponential relation between blood pressure and arterial diameter under stable physiological condition. (B) Linear relation between natural logarithm of systolic $\left(P_{s}\right)$ - diastolic $\left(P_{d}\right)$ pressure ratio $\left(\ln P_{s} / P_{d}\right)$ and arterial wall distensibility. Note: The increased slope (ie, stiffness parameter, $\beta$ ) in arteriosclerotic vessel compared to normal. $\beta$, which is the slope of the plot (Figure 1B), is theoretically independent of blood pressure at the time of measurement. ${ }^{31}$ Hence, the higher the value of $\beta$ the lower the compressibility (ie, the higher the stiffness) of the arterial wall, and the steeper the plot (Figure 1B). Clinically, since accurate assessment of arterial stiffness according to the change in vascular luminal diameter is hampered by the measurement on merely a local segment of artery and also the requirement for specific sonographic equipment, the proportional change in luminal diameter in Equation 8 can be replaced by substituting (7) into (8):

$$
\beta=\operatorname{In}\left(\mathrm{P}_{\mathrm{s}} / \mathrm{P}_{\mathrm{d}}\right) \cdot(2 \rho / \Delta \mathrm{P}) \cdot \mathrm{PWV}^{2} .
$$

For scale conversion from PWV, the following formula can be applied:

$$
\mathrm{CAVI}=\mathrm{a} \beta+\mathrm{b},
$$

where $\mathrm{a}$ and $\mathrm{b}$ are scale conversion constants. ${ }^{22,33}$

Hence, substituting (9) into (10) gives:

$$
\mathrm{CAVI}=\mathrm{a}\left[(2 \rho / \Delta \mathrm{P}) \cdot \operatorname{In}\left(\mathrm{P}_{\mathrm{s}} / \mathrm{P}_{\mathrm{d}}\right) \cdot \mathrm{PWV}^{2}\right]+\mathrm{b} .
$$

PWV: pulse wave velocity from valve orifice to ankle; $\mathrm{P}_{\mathrm{s}}$ : systolic blood pressure; $\mathrm{P}_{\mathrm{d}}$ : diastolic blood pressure; $\Delta \mathrm{P}$ : change in blood pressure; $\rho$ : blood density. ${ }^{22}$

\section{CAVI: data acquisition in testing subjects}

\section{Equipment}

The currently available equipment for measuring CAVI is model VaSera VS-1000 (Fukuda-Denshi Company, LTD, Tokyo, Japan) which is a portable machine resembling a cardiograph of dimensions $34.6 \mathrm{~cm}(\mathrm{~W}) \times 24.0 \mathrm{~cm}(\mathrm{D}) \times$ $15.4 \mathrm{~cm}(\mathrm{H})$ and weight $7.2 \mathrm{~kg}$ with print-out function. The ankle-brachial index (ABI) and PWV can also be obtained through the machine that has been reported to be able to achieve $3.8 \%$ of the average coefficient of variation among five repeated measurements. ${ }^{22}$

\section{Procedure and parameters of measurement}

A subject is allowed to assume a supine position with simultaneous blood pressure, electrocardiographic, and cardiac phonographic monitoring. Components required for the computation of CAVI can then be obtained, including systolic and diastolic blood pressures through the sphygmomanometer cuffs on the upper arm and ankle as well as PWV through dividing the distance between the aortic valve and the ankle 


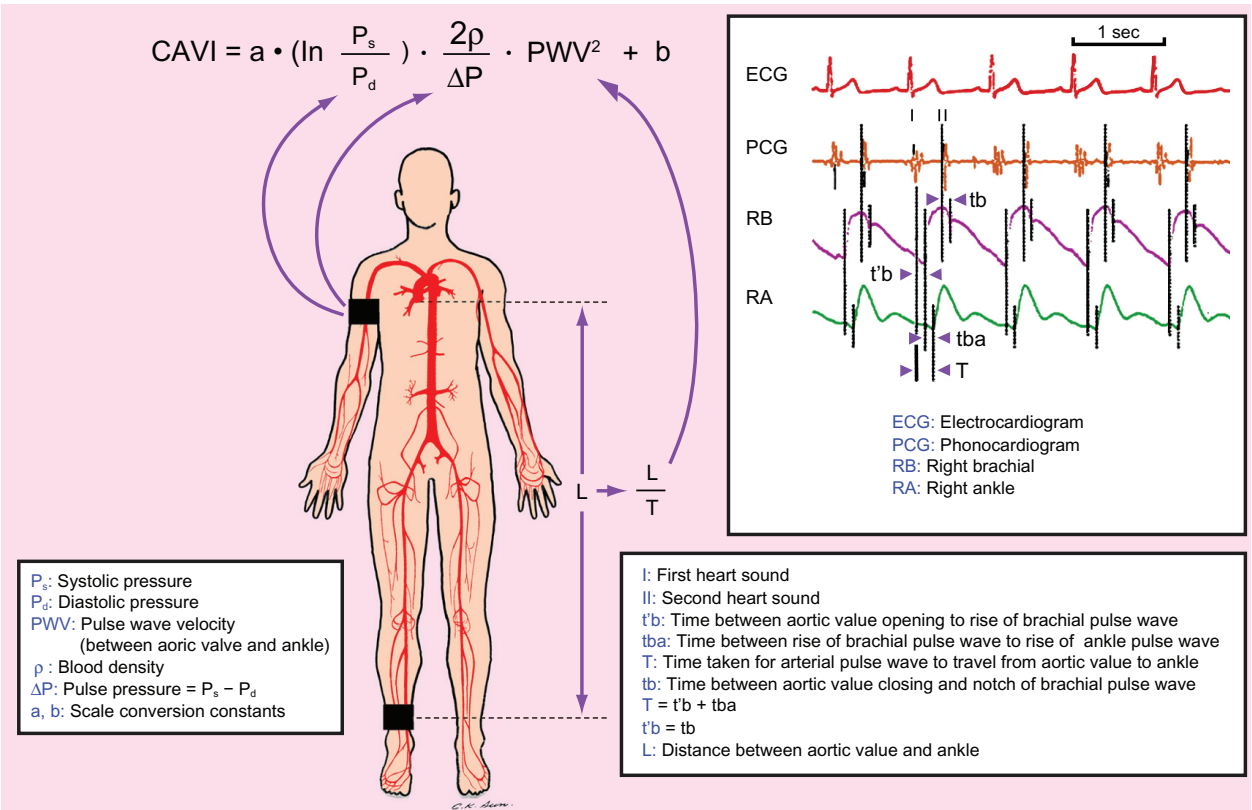

Figure 2 Schematic illustration of the acquisition of study parameters for computation of Cardio-Ankle Vascular Index (CAVI).

(ie, L) by the time during which PWV propagates that distance (ie, T) (Figure 2). T, in turn, can be calculated by the addition of the time between the opening of aortic valve detected on cardiac phonogram and the rise of the brachial pulse wave, $t^{\prime} \mathrm{b}$, and the time between the rise of the brachial pulse wave and the rise of the ankle pulse wave, tba. It is noteworthy that $\mathrm{t}^{\prime} \mathrm{b}$ and the time between the closing of aortic valve and the notch of the brachial pulse wave, tb, are theoretically equal (Figure 2) ${ }^{22}$ The scale conversion constants, a and b, in Equation 11 on previous page are computed automatically in the equipment.

\section{CAVI: data interpretation and precautions \\ Significance of results}

Equation 8 on previous page indicates that, theoretically, soft and flexible artery, which is considerably inflated by increased blood pressure, gives a low CAVI. Conceivably, arteriosclerotic artery, which is less inflated by an increase in blood pressure, gives a high value.

To establish the baseline CAVI scores according to age and gender in cardiovascular disease risk-free individuals as well as to compare the impact of cardiovascular pathologies on CAVI values, Namekata et al conducted a large-scale study on over 32 thousand individuals of age between 20 and 74 in Japan, including both sexes and those at different levels of risk for cardiovascular diseases after excluding those with history of heart disease, hypertension, stroke, diabetes, nephritis, and gout in $2011 .{ }^{33}$ The study concluded that the baseline CAVI scores from the cardiovascular disease risk-free group are useful to serve as normal control values for subsequent studies and that CAVI is a meaningful parameter to screen individuals with moderate to advanced arteriosclerosis. ${ }^{33}$

According to the manufacturer's instructions, a CAVI less than 8.0 is supposed to be normal, whereas a value less than 9.0 but more than (or equal to) 8.0 is considered "borderline". At the other end of the spectrum, a CAVI equal or more than 9.0 leads to the diagnosis of suspected arteriosclerosis. ${ }^{34}$

\section{Special circumstances in data interpretation}

It is noteworthy that while an elevated CAVI is considered pathological, a reduced value does not necessarily represent superior vascular function and may be pathognomonic of certain diseases. For instance, it has been reported that a negative correlation exists between CAVI and serum insulinlike growth factor-I level which is increased in acromegalic patients. The authors, therefore, concluded that CAVI may serve as a useful parameter for the assessment of therapeutic outcomes in patients with acromegaly. ${ }^{35}$

On the other hand, subjects with a low ankle-brachial index $(\mathrm{ABI})<0.9$ may have a severe arteriosclerotic femoral artery. These individuals may give a falsely low CAVI score $^{22}$ and, therefore, should be excluded from CAVI study. Under these circumstances, other noninvasive indices for 
the assessment of vascular function such as conventional or modified $\mathrm{PWV}^{36}$ and those involving evaluation of vascular endothelial function including forearm-mediated vasodilation $(\mathrm{FMD})^{37}$ and dilatation index (DI) $)^{38}$ may be utilized to provide additional information.

\section{CAVI: clinical and research applications}

\section{Application in patients with known} cardiovascular diseases and those at risk

Since its first introduction in 2004, CAVI has been widely applied to a variety of clinical studies particularly those involving the assessment of arterial stiffness in patients with established cardiovascular diseases and those at high risks for disease development. ${ }^{39}$

\section{Coronary heart disease}

CAVI has been used to study patients with coronary heart disease which is the most notorious life-threatening condition in the developed world. Not only has CAVI been found to reflect plaque burden in the coronary artery of patients with an established diagnosis of coronary heart disease, ${ }^{40,41}$ it has also been demonstrated to be an independent parameter positively associated with coronary artery calcium score (CACS) and the degree of stenosis which reflects coronary atherosclerosis in asymptomatic subjects with abnormal glucose metabolism. ${ }^{42}$ The clinical significance of CAVI in the assessment of patients with coronary heart disease has been further augmented by the discovery of its independent association with the Syntax score, which is a prognostic marker in patients with acute coronary syndrome, while neither traditional cardiovascular risk factor nor thrombolysis in myocardial infarction (TIMI) risk score was independent determinant of the Syntax score..$^{43}$ The findings, therefore, suggest that CAVI can be a useful tool not only to assess plaque burden in the coronary artery of patients with known coronary heart disease, ${ }^{40,41}$ but also to evaluate their prognosis and also the risk for subclinical coronary atherosclerosis in asymptomatic subjects. ${ }^{42,43}$ Finally, compared to baPWV, CAVI has been reported to be superior because of its significant correlation with left ventricular function and serum lipid profile as well as its discriminating ability for patients with angina pectoris out of all subjects with the complaint of chest pain. ${ }^{44}$

\section{Cerebrovascular disease}

Cerebrovascular disease, another flagrant killer in the industrialized nations, has also been studied with CAVI. The clini- cal significance of CAVI in this aspect is not the evaluation of the severity of a full-blown disease, but its capability of detecting subtle and subclinical intracranial vascular pathologies instead. In addition to being an independent factor associated with cerebral microbleeds in patients with acute ischemic stroke, ${ }^{45} \mathrm{CAVI}$ has also been shown to be independently correlated with silent brain infarct. ${ }^{46}$ Moreover, the presence of cerebral small vessel diseases in asymptomatic young and middle-aged subjects has also been found to be significantly associated with their CAVI scores. ${ }^{47}$ Hence, the results of these studies indicate that, although CAVI is considered an indicator of arteriosclerosis in the major arteries between the aortic valve and the ankle, it may reflect the severity of cerebral arteriolosclerosis. It is noteworthy that CAVI has also been successfully applied to the evaluation of vascular recovery after intensive rehabilitation in chronic stroke patients. ${ }^{48}$

\section{Hypertension}

Other than the potentially life-threatening diseases mentioned above, CAVI has also been utilized in the assessment of vascular health for those at risk of developing subsequent adverse cardiovascular outcomes. Hypertension, for instance, is by far one of the most frequently mentioned conditions associated with vascular stiffness and occupies the contents of nearly one-third of all CAVI-related literature. Positive correlations of CAVI with causative factors such as markers of inflammation and oxidative stress, ${ }^{49-51}$ indicator of left ventricular afterload, ${ }^{52}$ and dysfunctions of other organ systems ${ }^{53}$ in hypertensive patients have already been reported. In addition, CAVI has also been used to investigate special populations at risk of developing hypertension. For example, Yoshida et al showed the superiority of CAVI over the conventional baPWV in differentiating preeclamptic from chronic hypertensive pregnant women..$^{54}$ Accordingly, CAVI has been adopted as a parameter for following treatment outcomes in hypertensive patients..$^{55-57}$ The therapeutic potential of alternative treatment strategies against hypertension has also been evaluated with CAVI. ${ }^{58}$

\section{Diabetes mellitus}

The association of CAVI with the disease progression of diabetes mellitus, which is another well-known condition that contributes to vascular stiffness, has also been extensively studied. Indeed, nearly one-fourth of CAVIrelated publications retrieved from the PubMed database have mentioned diabetes in their contents. Not only has CAVI been proposed to better reflect the status of diabetes control compared to baPWV, ${ }^{20}$ it has also been reported to be sensitive in detecting diabetes-associated complications. 
For instance, diabetic peripheral neuropathy was found to be significantly associated with an elevated CAVI without notable carotid intimal changes in patients with type 2 diabetes. ${ }^{59}$ Moreover, an increased CAVI has also been shown to be correlated with microalbuminuria in type 2 diabetic patients, ${ }^{60}$ underscoring the ability of CAVI in reflecting diabetes-related microvascular complications. In terms of the etiologies of diabetes-related arterial stiffness, not only has CAVI been demonstrated to be significantly correlated with the duration of diabetes, blood pressure, and serum total cholesterol level, but it has also been found to be positively associated with the concentrations of acute-phase reactants including high-sensitivity C-reactive protein, amyloid A protein, sialic acid, fibrinogen, and white blood cells that are known contributors to atherosclerosis in patients with type 2 diabetes mellitus. ${ }^{61}$ Furthermore, CAVI has been utilized in assessing the effectiveness of pharmacological strategies against arterial stiffness in patients with type 2 diabetes. ${ }^{62,63}$

\section{Metabolic syndrome and obesity}

On the other hand, CAVI has also been shown to correlate positively with waist circumference and the number of components for the diagnosis of metabolic syndrome. ${ }^{64}$ In addition, another study designed to identify the missing link between patients with obstructive sleep apnea and their elevated cardiovascular risks demonstrated that plasma level of pentraxin3, an indicator of inflammation, was independently correlated with CAVI. ${ }^{65}$ The value of CAVI in monitoring the treatment outcomes for these patients has also been demonstrated. ${ }^{64-66}$ Furthermore, CAVI has been reported to reflect the positive therapeutic impact of diet supplement on vascular health in obese subjects. ${ }^{67}$

\section{Aging}

Beside hypertension and diabetes, age is a well-known factor that contributes to an increased CAVI. ${ }^{33,68,69}$ Age-related widening of pulse pressure is believed to be the major cause of age-related increase in prevalence of hypertension and has been attributed to arterial stiffening. ${ }^{8}$ The results of a study on over 32 thousand Japanese subjects of age between 20 and 74 including both genders in 2011 not only showed that the proportion of cardiovascular disease risk-free subjects to all subjects decreased as age increased, but also a linear increase in the average age-specific baseline scores of CAVI in the cardiovascular disease risk-free group in both genders as their age advanced. Moreover, the average age-specific baseline scores of CAVI in the cardiovascular disease risk-free group were significantly greater among men than among women. Furthermore, as expected, the average agespecific baseline scores of CAVI in the cardiovascular disease high-risk group were significantly higher than those in the cardiovascular disease risk-free group in both genders of age over $40 .{ }^{33}$ Another study conducted in patients under general anesthesia showed that CAVI was not reduced significantly in patients of age over 65 in comparison with their younger counterparts. ${ }^{23}$ As CAVI is affected by a change in vascular tone, the sluggishness of the arterial wall to relax more likely represents age-related sclerosis of the arterial wall in the aged population after exclusion of possible smooth muscle contraction after general anesthesia. ${ }^{70}$ Regarding the topic of aging in occupational and rehabilitation medicine, CAVI has been successfully applied to both longitudinal ${ }^{73}$ and crosssectional $^{72}$ studies that focused on the elderly population.

\section{Chronic kidney disease}

Since cardiovascular diseases are the major causes of death in patients with chronic kidney diseases, monitoring arterial stiffness helps in detecting the presence and following the progression of cardiovascular pathologies in this patient population. However, the accuracy of conventional noninvasive arterial stiffness parameters such as PWV and baPWV are confounded by the elevated blood pressure in patients with renal diseases. CAVI, on the other hand, appears to be the parameter of choice because of its independence of blood pressure changes. A study on patients under chronic hemodialysis established a CAVI score of 7.55 as the cut-off value for suspecting the presence of cardiovascular diseases, ${ }^{73}$ highlighting the use of CAVI as a screening parameter that would help in guiding subsequent treatment. Another investigation of cardiac dysfunction in patients on chronic hemodialysis demonstrated the successful application of CAVI in distinguishing patients with significant diastolic dysfunction from those without. ${ }^{74}$

Taken together, it is obvious that not only has CAVI been adopted to quantitatively assess the severity of atherosclerosis in patients with known cardiovascular diseases, it also plays a significant role in following disease progression and treatment outcomes at a subclinical level for those at risk.

\section{Extension of application}

On the other hand, using the term "Cardio-Ankle Vascular Index" to search for the relevant literature in the PubMed database showed that the number of publications related to CAVI has been on the rise in recent years, ${ }^{16}$ highlighting its increasing popularity as a reliable indicator of arterial stiffness (Figure 3). Indeed, CAVI-related publications are 


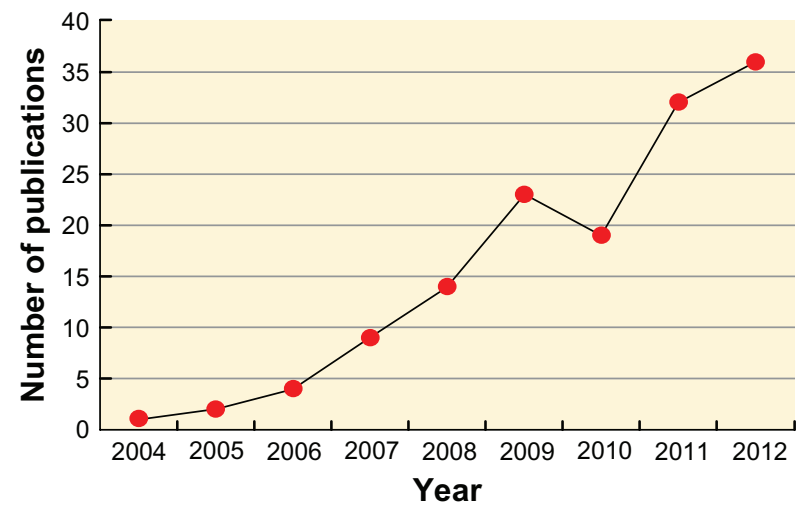

Figure 3 Changes in the number of Cardio-Ankle Vascular Index (CAVI)-related publications in the PubMed database since 2004.

even more when those not included in the PubMed domain are taken into consideration.

The boost in literature can also be explained by the expanding application of CAVI not just to the evaluation of vascular function in subjects with established diagnoses of cardiovascular diseases and those at risk as mentioned previously, but also in other conditions that increased arterial stiffness at an early stage, such as large vessel vasculitis. ${ }^{75}$ Moreover, the application has further been extended to include normal subjects exposed to factors of unknown cardiovascular influence. For instance, CAVI has been used to assess the vascular status in healthy individuals with a genetic predisposition to cardiovascular diseases, such as heterozygous familial hypercholesterolemia. ${ }^{76}$ Other interesting studies also include the use of CAVI in comparing arterial stiffness between subjects of different ethnicities ${ }^{77,78}$ and those of the same ethnic group but of different geographical locations. ${ }^{79}$

Furthermore, other than arterial stiffness, the scope of CAVI-related investigation goes further to include the general population. Not only has it been proposed to be a screening tool for atherosclerosis by Kadota et al based on their findings from over a thousand adults who showed strongly significant associations of CAVI scores with carotid intima-media thickness and homocysteine after adjustment for age and sex ${ }^{69}$ it has also been demonstrated to display significant negative correlation with renal function in apparently healthy subjects. ${ }^{80}$ In addition, the correlation between CAVI and chronic inflammation has also been investigated in asymptomatic subjects who were found to exhibit a positive association between a subclinical impairment in vascular health represented by an elevated CAVI and a chronic inflammatory state as reflected in their increased concentrations of serum amyloid $\mathrm{A}^{81}$ as well as high-sensitivity $\mathrm{C}$-reactive protein. ${ }^{82}$ Besides, CAVI has been successfully applied to the evaluation of the impact of extrinsic factors such as environmental particles in normal individuals. ${ }^{83}$

Despite the lack of difference in arterial stiffness between the study groups as measured by conventional parameters, CAVI has been shown to reflect subtle differences at metabolic ${ }^{20,64}$ and cellular levels. ${ }^{19}$ It is, therefore, not surprising that it can be used in the general population for detecting and assessing the severity of subclinical vascular anomalies. Being blood pressure-independent may be one of the bestowed merits that enhance its sensitivity and extend its applicability for these purposes.

\section{Clinical and research significance}

Provided that CAVI is sensitive in discerning subtle functional ${ }^{19}$ and organic ${ }^{84}$ changes in major arteries before actual functional impairment, it is invaluable in preventive medicine. Not only can it be used to quantitatively assess the extent of arteriosclerosis in the major arteries between the aortic valve and the ankle in patients with known cardiovascular diseases, but it can also be applied to the screening of individuals at a subclinical stage. ${ }^{33}$ After a baseline value has been established, subsequent follow-ups of the CAVI scores can then serve as reliable indicators of disease progression that are valuable in evaluating the outcomes after physical ${ }^{48}$ or pharmacological ${ }^{85-87}$ treatment. The cardiovascular impact of intrinsic ${ }^{35,76}$ or extrinsic ${ }^{58,67,83}$ factors can also be evaluated in well-controlled studies.

\section{CAVI: limitations in application Potential variations and errors in data interpretation}

A study on over 200 healthy Japanese and an equivalent number of Russian counterparts has demonstrated a significantly elevated CAVI in the Russian subjects. ${ }^{77}$ Although it seems reasonable to conclude that the Russian examinees were at an increased risk for cardiovascular diseases when higher disease prevalence in Russia compared to that in Japan was taken into account, ${ }^{77}$ anthropometric and genetic variations of ethnic origins that may contribute to the difference in CAVI scores between the two groups cannot be completely ruled out. In addition, genetic difference in disease susceptibility and response among different ethnic groups may exist. Two other studies involving the comparison of CAVI between healthy Mongolian and Japanese subjects ${ }^{78}$ and those with hypertension and diabetes mellitus ${ }^{88}$ also raise the same concern. Indeed, of the 140 CAVI-related publications retrieved from the PubMed database, the vast 
majority are of Asian origins, mostly Japan. In addition to the novelty and limited availability of the equipment, a lack of reliable databases of specific ethnic groups for reference may be another reason for the dearth of CAVI-related research in non-Asian countries.

\section{Limitations}

Since CAVI reflects both organic and functional stiffness, it is inappropriate to consider it a pure indicator of organic changes in the arterial wall as in arteriosclerosis and aging. ${ }^{25}$ Although the index is independent of blood pressure, it is affected by the state of smooth muscle contraction as reflected in the changes in vascular tone. ${ }^{26}$ Caution, therefore, has to be taken in data interpretation. On the other hand, since an increased sympathetic tone is characteristic of some disease entities as in resistant hypertension and heart failure, ${ }^{89}$ the ability of CAVI to record the changes may be a distinct advantage rather than a limitation under these circumstances.

\section{CAVI: future direction and speculations}

In addition to being a validated blood pressure-independent parameter for assessing arterial stiffness, CAVI has also served as a useful tool for supporting the reliability and validity of novel methodologies in the evaluation of arterial stiffness and cardiovascular risks. ${ }^{36,90-93}$ In this way, CAVI helps in the development of new diagnostic technologies in cardiovascular medicine.

On the other hand, provided that significant ethnic differences exist in CAVI, ${ }^{33,77,78}$ anthropometrical variations among individuals of different ethnic origins may have to be taken into account. Thus, reliable database from studies on large populations of different ethic groups other than that of Asians may have to be established to extend the application of CAVI as a reliable tool for assessing arterial stiffness to a global scale. This is of importance especially when considering the fact that an industrialized western nation like the United States has a remarkably higher mortality from coronary heart disease compared to that in Japan where the available database was built. ${ }^{33}$

The acceptance of CAVI as a reliable tool for early identification of cardiovascular diseases worldwide may be a major breakthrough in preventive medicine because it triggers the alarm at an early stage ${ }^{43}$ and allows timely treatment as well as modification in lifestyle. ${ }^{94}$ Furthermore, for subjects with known cardiovascular diseases and also those at high risk, CAVI may be a sensitive indicator in following disease progression $^{80,95}$ and monitoring treatment outcomes. ${ }^{48,85-87}$ Since a large-scaled study has only been recently performed to establish a reliable database for the Asian population, ${ }^{33}$ it is anticipated that CAVI-related research will continue to bloom for the coming years.

\section{Conclusion}

CAVI has been widely applied clinically to assess arterial stiffness in myriad populations with known cardiovascular diseases including subjects with diagnosed atherosclerosis, coronary heart disease, and stroke as well as those at risk, including those with hypertension, diabetes, the elderly, and the obese. Because of its sensitivity, not only has the index been used to discern subtle changes in the disease process, it has also been utilized in studying normal individuals to assess their potential risks of developing cardiovascular diseases. The primary aims of assessing arterial stiffness using CAVI are not merely to aid in early detection of arteriosclerosis to allow timely treatment and change in lifestyle, but also to quantitatively evaluate the progression of disease and the effectiveness of treatment. In spite of its merit of being unaffected by blood pressure, discretion in data interpretation is suggested because an elevated CAVI represents not just vascular stiffness caused by pathological changes in the arterial wall, it can also be attributed to an increased vascular tone brought about by smooth muscle contraction. Finally, certain patient populations, such as those with an $\mathrm{ABI}<0.9$, may give falsely low CAVI and are suggested to be excluded from study.

\section{Disclosure}

The author reports no conflicts of interest in this work.

\section{References}

1. Cecelja M, Chowienczyk P. Dissociation of aortic pulse wave velocity with risk factors for cardiovascular disease other than hypertension: a systematic review. Hypertension. 2009;54(6):1328-1336.

2. van Popele NM, Grobbee DE, Bots ML, et al. Association between arterial stiffness and atherosclerosis: the Rotterdam Study. Stroke. 2001; 32(2):454-460

3. Avolio AP, Chen SG, Wang RP, Zhang CL, Li MF, O'Rourke MF. Effects of aging on changing arterial compliance and left ventricular load in a northern Chinese urban community. Circulation. 1983;68(1):50-58

4. Mitchell GF, Parise H, Benjamin EJ, et al. Changes in arterial stiffness and wave reflection with advancing age in healthy men and women: the Framingham Heart Study. Hypertension. 2004;43(6):1239-1245.

5. Yasmin, McEniery CM, O'Shaughnessy KM, et al. Variation in the human matrix metalloproteinase- 9 gene is associated with arterial stiffness in healthy individuals. Arterioscler Thromb Vasc Biol. 2006; 26(8):1799-1805

6. O'Rourke MF, Hashimoto J. Mechanical factors in arterial aging: a clinical perspective. J Am Coll Cardiol. 2007;50(1):1-13.

7. Corman B, Duriez M, Poitevin P, et al. Aminoguanidine prevents age-related arterial stiffening and cardiac hypertrophy. Proc Natl Acad Sci U S A. 1998;95(3):1301-1306. 
8. Cecelja M, Chowienczyk P. Role of arterial stiffness in cardiovascular disease. J R Soc Med Cardiovasc Dis. 2012;1:11.

9. Dogui A, Kachenoura N, Frouin F, et al. Consistency of aortic distensibility and pulse wave velocity estimates with respect to the Bramwell-Hill theoretical model: a cardiovascular magnetic resonance study. J Cardiovasc Magn Reson. 2011;13:11.

10. Laurent S, Cockcroft J, Van Bortel L, et al. Expert consensus document on arterial stiffness: methodological issues and clinical applications. Eur Heart J. 2006;27(21):2588-2605.

11. Blacher J, Asmar R, Djane S, London GM, Safar ME. Aortic pulse wave velocity as a marker of cardiovascular risk in hypertensive patients. Hypertension. 1999;33(5):1111-1117.

12. Mancia G, De Backer G, Dominiczak A, et al. 2007 Guidelines for the Management of Arterial Hypertension: The Task Force for the Management of Arterial Hypertension of the European Society of Hypertension (ESH) and of the European Society of Cardiology (ESC). J Hypertens. 2007;25(6):1105-1187.

13. McDonald DA. Blood Flow in Arteries, 2nd ed. Edward Arnold. 1974.

14. Bramwell JC, Hill AV. Velocity transmission of the pulse wave and elasticity of arteries. Lancet. 1922;199(5149):891-892.

15. Milnor WR. Hemodynamics, 2nd ed. Williams and Wilkins: Baltimore. 1989.

16. Yambe T, Yoshizawa M, Saijo Y, et al. Brachio-ankle pulse wave velocity and cardio-ankle vascular index (CAVI). Biomed Pharmacother. 2004;58 Suppl 1:S95-S98.

17. Laogun AA, Newman DL, Gosling RG. Comparison of pulse wave velocity measured by Doppler shifted ultrasound and electromagnetic flowmetry. Ultrasound Med Biol. 1978;3(4):367-371.

18. Bergel DH. The static elastic properties of the arterial wall. J Physiol. 1961;156(3):445-457.

19. Takahashi M, Shiba T, Hirano K, Hitsumoto T, Shirai K. Acute decrease of cardio-ankle vascular index with the administration of beraprost sodium. J Atheroscler Thromb. 2012;19(5):479-484.

20. Ibata J, Sasaki H, Kakimoto T, et al. Cardio-ankle vascular index measures arterial wall stiffness independent of blood pressure. Diabetes Res Clin Pract. 2008;80(2):265-270.

21. Asmar R. Arterial Stiffness and Pulse Wave Velocity: Clinical Applications. Amsterdam, The Netherlands. Elsevier. 1999.

22. Shirai K, Utino J, Otsuka K, Takata M. A novel blood pressureindependent arterial wall stiffness parameter; cardio-ankle vascular index (CAVI). J Atheroscler Thromb. 2006;13(2):101-107.

23. Kim B, Takada K, Oka S, Misaki T. Influence of blood pressure on cardioankle vascular index (CAVI) examined based on percentage change during general anesthesia. Hypertens Res. 2011;34(6):779-783.

24. Shirai K. Analysis of vascular function using the cardio-ankle vascular index (CAVI). Hypertension Research. 2011;34:684-685.

25. Shirai K, Song M, Suzuki J, et al. Contradictory effects of beta1- and alpha1-aderenergic receptor blockers on cardio-ankle vascular stiffness index (CAVI) - CAVI independent of blood pressure. $J$ Atheroscler Thromb. 2011;18(1):49-55.

26. Frank OD. Die Theorie de Pulswellen. [The Pulsewellen Theory]. Ztschr Biol. 1926; 85:91-130. German.

27. Gosling RG, Budge MM. Terminology for describing the elastic behavior of arteries. Hypertension. 2003;41(6):1180-1182.

28. Bramwell JC, Hill AV. The velocity of the pulse wave in man. Proc $R$ Soc Lond B. 1922;93:298-306.

29. Merillon JP, Fontenier GJ, Lerallut JF, et al. Aortic input impedance in normal man and arterial hypertension: its modification during changes in aortic pressure. Cardiovasc Res. 1982;16(11):646-56.

30. Hayashi G, Sato N, Niimi H, Handa H, Moritake K, Okumura A. Analysis of vascular wall constitutive law with finite deformation theory. Medical Electronics and Biological Engineering. 1975;13: 293-297.

31. Kawasaki T, Takeuchi K, Hasegawa M, Yagi S, Nakayama S, Takayama Y. Noninvasive measurement of common carotid artery effect with echo phase tracking system. Journal of Japanese College of Angiology. 1982;22:241-248.
32. Roach MR, Burton AC. The reason for the shape of the distensibility curves of arteries. Can J Biochem Physiol. 1957;35(8):681-690.

33. Namekata T, Suzuki K, Ishizuka N, Shirai K. Establishing baseline criteria of cardio-ankle vascular index as a new indicator of arteriosclerosis: a cross-sectional study. BMC Cardiovasc Disord. 2011;11:51

34. Fukuda-Denshi Company L, Tokyo, Japan. http://www.fukuda.co.jp/ english/products/special_features/vasera/cavi.html. Accessed April 16, 2013.

35. Matsuda Y, Kawate H, Matsuzaki C, et al. Reduced arterial stiffness in patients with acromegaly: non-invasive assessment by the cardio-ankle vascular index (CAVI). Endocr J. 2012.

36. Wu HT, Hsu PC, Liu AB, et al. Six-channel ECG-based pulse wave velocity for assessing whole-body arterial stiffness. Blood Press. 2012; 21(3):167-176.

37. Huck CJ, Bronas UG, Williamson EB, Draheim CC, Duprez DA, Dengel DR. Noninvasive measurements of arterial stiffness: repeatability and interrelationships with endothelial function and arterial morphology measures. Vasc Health Risk Manag. 2007; 3(3):343-349.

38. Wu HT, Lee $\mathrm{CH}$, Liu AB, et al. Arterial stiffness using radial arterial waveforms measured at the wrist as an indicator of diabetic control in the elderly. IEEE Trans Biomed Eng. 2010;58(2):243-252.

39. Hayashi S. Significance of plasma D-dimer in relation to the severity of atherosclerosis among patients evaluated by non-invasive indices of cardio-ankle vascular index and carotid intima-media thickness. Int $J$ Hematol. 2010;92(1):76-82.

40. Horinaka S, Yabe A, Yagi H, et al. Cardio-ankle vascular index could reflect plaque burden in the coronary artery. Angiology. 2011; 62(5):401-408.

41. Nakamura K, Tomaru T, Yamamura S, Miyashita Y, Shirai K, Noike H. Cardio-ankle vascular index is a candidate predictor of coronary atherosclerosis. Circ J. 2008;72(4):598-604.

42. Park HE, Choi SY, Kim MK, Oh BH. Cardio-ankle vascular index reflects coronary atherosclerosis in patients with abnormal glucose metabolism: Assessment with 256 slice multi-detector computed tomography. J Cardiol. 2012;60(5):372-376.

43. Korkmaz L, Adar A, Korkmaz AA, et al. Atherosclerosis burden and coronary artery lesion complexity in acute coronary syndrome patients. Cardiol J. 2012;19(3):295-300.

44. Takaki A, Ogawa H, Wakeyama T, et al. Cardio-ankle vascular index is superior to brachial-ankle pulse wave velocity as an index of arterial stiffness. Hypertens Res. 2008;31(7):1347-1355.

45. Shimoyama T, Iguchi Y, Kimura K, et al. Stroke patients with cerebral microbleeds on MRI scans have arteriolosclerosis as well as systemic atherosclerosis. Hypertens Res. 2012;35(10):975-979.

46. Saji N, Kimura K, Shimizu H, Kita Y. Silent brain infarct is independently associated with arterial stiffness indicated by cardio-ankle vascular index (CAVI). Hypertens Res. 2012;35(7):756-760.

47. Choi SY, Park HE, Seo H, Kim M, Cho SH, Oh BH. Arterial Stiffness Using Cardio-Ankle Vascular Index Reflects Cerebral Small Vessel Disease in Healthy Young and Middle Aged Subjects. $J$ Atheroscler Thromb. 2012.

48. Takatori K, Matsumoto D, Okada Y, Nakamura J, Shomoto K. Effect of intensive rehabilitation on physical function and arterial function in community-dwelling chronic stroke survivors. Top Stroke Rehabil. 2012;19(5):377-383.

49. Okura T, Watanabe S, Kurata M, et al. Relationship between cardio-ankle vascular index (CAVI) and carotid atherosclerosis in patients with essential hypertension. Hypertens Res. 2007;30(4): 335-340.

50. Masugata H, Senda S, Murao K, et al. Association between Urinary 8-Hydroxydeoxyguanosine, an Indicator of Oxidative Stress, and the Cardio-Ankle Vascular Index in Hypertensive Patients. J Atheroscler Thromb. 2012;19(8):747-755.

51. Kotani K, Yamada S, Yamada T, Kario K, Taniguchi N. Oxidized lipoprotein(a) and cardio-ankle vascular index (CAVI) in hypertensive subjects. Heart Vessels. 2012. [Epub ahead of print.] 
52. Masugata $\mathrm{H}$, Senda $\mathrm{S}$, Inukai $\mathrm{M}$, et al. Association of cardio-ankle vascular index with brain natriuretic peptide levels in hypertension. J Atheroscler Thromb. 2012;19(3):255-262.

53. Masugata H, Senda S, Okada H, et al. Association between arterial stiffness and pulmonary function in hypertensive patients. Hypertens Res. 2012;35(4):388-392.

54. Yoshida A, Sugiyama T, Sagawa N. Assessment of the cardioankle vascular index in pregnant women complicated with hypertensive disorders. ISRN Obstet Gynecol. 2011;Article ID 919816:1-5.

55. Ishimitsu T, Numabe A, Masuda T, et al. Angiotensin-II receptor antagonist combined with calcium channel blocker or diuretic for essential hypertension. Hypertens Res. 2009;32(11):962-968.

56. Kinouchi K, Ichihara A, Bokuda K, Kurosawa H, Itoh H. Differential Effects in Cardiovascular Markers between High-Dose Angiotensin II Receptor Blocker Monotherapy and Combination Therapy of ARB with Calcium Channel Blocker in Hypertension (DEAR Trial). Int $J$ Hypertens. 2011:284823.

57. Kinouchi K, Ichihara A, Sakoda M, Kurauchi-Mito A, Murohashi-Bokuda K, Itoh H. Effects of telmisartan on arterial stiffness assessed by the cardio-ankle vascular index in hypertensive patients. Kidney Blood Press Res. 2010;33(4):304-312.

58. Xu Y, Yan H, Yao J, et al. Cardio Ankle Vascular Index evaluations revealed that co-treatment of ARB Anti-hypertension medication with Traditional Chinese Medicine improved arterial functionality. J Cardiovasc Pharmacol. 2012.

59. Kim ES, Moon SD, Kim HS, et al. Diabetic peripheral neuropathy is associated with increased arterial stiffness without changes in carotid intima-media thickness in type 2 diabetes. Diabetes Care. 2011; 34(6):1403-1405.

60. Kim KJ, Lee BW, Kim HM, et al. Associations between cardio-ankle vascular index and microvascular complications in type 2 diabetes mellitus patients. J Atheroscler Thromb. 2011;18(4):328-336.

61. Wakabayashi I, Masuda H. Association of acute-phase reactants with arterial stiffness in patients with type 2 diabetes mellitus. Clin Chim Acta. 2006;365(1-2):230-235

62. Uehara G, Takeda H. Relative effects of telmisartan, candesartan and losartan on alleviating arterial stiffness in patients with hypertension complicated by diabetes mellitus: an evaluation using the cardio-ankle vascular index (CAVI). J Int Med Res. 2008;36(5):1094-1102.

63. Miyashita Y, Endo K, Saiki A, et al. Effect of ezetimibe monotherapy on lipid metabolism and arterial stiffness assessed by cardio-ankle vascular index in type 2 diabetic patients. J Atheroscler Thromb. 2010; 17(10):1070-1076.

64. Liu H, Zhang X, Feng X, Li J, Hu M, Yambe T. Effects of metabolic syndrome on cardio-ankle vascular index in middle-aged and elderly Chinese. Metab Syndr Relat Disord. 2011;9(2):105-110.

65. Kasai T, Inoue K, Kumagai T, et al. Plasma pentraxin 3 and arterial stiffness in men with obstructive sleep apnea. Am J Hypertens. 2011;24(4):401-407.

66. Yoshihisa A, Suzuki S, Yamaki T, et al. Impact of adaptive servo-ventilation on cardiovascular function and prognosis in heart failure patients with preserved left ventricular ejection fraction and sleep-disordered breathing. Eur J Heart Fail. 2012.

67. Usui T, Tochiya M, SasakiY, et al. Effects of natural S-equol supplements on overweight or obesity and metabolic syndrome in the Japanese, based on sex and equol status. Clin Endocrinol (Oxf). 2012.

68. Shiba T, Takahashi M, Hori Y, Maeno T, Shirai K. Optic Nerve Head Circulation Determined by Pulse Wave Analysis is Significantly Correlated with Cardio Ankle Vascular Index, Left Ventricular Diastolic Function, and Age. J Atheroscler Thromb. 2012.

69. Kadota K, Takamura N, Aoyagi K, et al. Availability of cardio-ankle vascular index (CAVI) as a screening tool for atherosclerosis. Circ J. 2008;72(2):304-308.

70. Shirai K. Analysis of vascular function using the cardio-ankle vascular index (CAVI). Hypertens Res. 2011;34(6):684-685.

71. Lindholm H, Punakallio A, Lusa S, Sainio M, Ponocny E, Winker R. Association of cardio-ankle vascular index with physical fitness and cognitive symptoms in aging Finnish firefighters. Int Arch Occup Environ Health. 2012;85(4):397-403.
72. Kawano H, Iemitsu M, Gando Y, et al. Habitual rowing exercise is associated with high physical fitness without affecting arterial stiffness in older men. J Sports Sci. 2012;30(3):241-246.

73. Takenaka T, Hoshi H, Kato N, et al. Cardio-ankle vascular index to screen cardiovascular diseases in patients with end-stage renal diseases. J Atheroscler Thromb. 2008;15(6):339-344.

74. Kimura H, Takeda K, Tsuruya K, et al. Left ventricular mass index is an independent determinant of diastolic dysfunction in patients on chronic hemodialysis: a tissue Doppler imaging study. Nephron Clin Pract. 2011;117(1):c67-c73.

75. Masugata H, Senda S, Himoto T, et al. Detection of increased arterial stiffness in a patient with early stage of large vessel vasculitis by measuring cardio-ankle vascular index. Tohoku J Exp Med. 2009; 219(2):101-105.

76. Soska V, Dobsak P, Dusek L, et al. Cardio-ankle vascular index in heterozygous familial hypercholesterolemia. J Atheroscler Thromb. 2012;19(5):453-461.

77. Liu H, Saijo Y, Zhang X, et al. Comparative analysis of cardio-ankle vascular index between Japanese and Russians. In: Esashi M, K. I, Ohuchi N, Osumi N, Sato M, Yamaguchi T, editors. Future Medical Engineering Based on Bionanotechnology: Proceedings of the Final Symposium of the Tohoku University 21st Century Center of Excellence Program. Imperial College Press: London. 2006:411-418.

78. Uurtuya S, Taniguchi N, Kotani K, et al. Comparative study of the cardio-ankle vascular index and ankle-brachial index between young Japanese and Mongolian subjects. Hypertens Res. 2009;32(2):140-144.

79. Hirasada K, Niimura H, Kubozono T, et al. Values of cardio-ankle vascular index (CAVI) between Amami islands and Kagoshima mainland among health checkup examinees. J Atheroscler Thromb. 2012;19(1):69-80.

80. Kubozono T, Miyata M, Ueyama K, et al. Association between arterial stiffness and estimated glomerular filtration rate in the Japanese general population. J Atheroscler Thromb. 2009;16(6):840-845.

81. Kotani K, Yamada T, Miyamoto M, Kario K, Ishibashi S, Taniguchi N. The correlation between the cardio-ankle vascular index (CAVI) and serum amyloid A in asymptomatic Japanese subjects. Heart Vessels. 2012;27(5):499-504.

82. Higashiyama A, Wakabayashi I, Kubota Y, et al. Does High-Sensitivity C-Reactive Protein or Low-Density Lipoprotein Cholesterol Show a Stronger Relationship with the Cardio-Ankle Vascular Index in Healthy Community Dwellers?: the KOBE Study. J Atheroscler Thromb. 2012.

83. Wu CF, Li YR, Kuo IC, Hsu SC, Lin LY, Su TC. Investigating the association of cardiovascular effects with personal exposure to particle components and sources. Sci Total Environ. 2012;431:176-182.

84. Taguchi M, Ishigami M, Nishida M, Moriyama T, Yamashita S, Yamamura T. Remnant lipoprotein-cholesterol is a predictive biomarker for large artery atherosclerosis in apparently healthy women: usefulness as a parameter for annual health examinations. Ann Clin Biochem. 2011; 48(Pt 4):332-337.

85. Obayashi S, Terauchi M, Kato K, Akiyoshi M, Kubota T. Raloxifene temporarily reduces arterial stiffness. J Obstet Gynaecol Res. 2010; 36(6):1229-1235.

86. Nagayama D, Saiki A, Endo K, et al. Improvement of cardio-ankle vascular index by glimepiride in type 2 diabetic patients. Int J Clin Pract. 2010;64(13):1796-1801.

87. Miyoshi T, Doi M, Hirohata S, et al. Olmesartan reduces arterial stiffness and serum adipocyte fatty acid-binding protein in hypertensive patients. Heart Vessels. 2011;26(4):408-413.

88. Uurtuya S, Kotani K, Taniguchi N, et al. Comparative study of atherosclerotic parameters in Mongolian and Japanese patients with hypertension and diabetes mellitus. J Atheroscler Thromb. 2010; 17(2):181-188.

89. Parati G, Esler M. The human sympathetic nervous system: its relevance in hypertension and heart failure. Eur Heart J. 2012; 33(9):1058-1066.

90. Park HE, Choi SY, Kim HS, Kim MK, Cho SH, Oh BH. Epicardial fat reflects arterial stiffness: assessment using 256-slice multidetector coronary computed tomography and cardio-ankle vascular index. J Atheroscler Thromb. 2012;19(6):570-576. 
91. Korkmaz L, Erkan H, Korkmaz AA, et al. Relationship of aortic knob width with cardio-ankle vascular stiffness index and its value in diagnosis of subclinical atherosclerosis in hypertensive patients: a study on diagnostic accuracy. Anadolu Kardiyol Derg. 2012;12(2):102-106.

92. Himeno A, Satoh-Asahara N, Usui T, et al. Salivary cortisol levels are associated with outcomes of weight reduction therapy in obese Japanese patients. Metabolism. 2012;61(2):255-261.

93. Masugata H, Senda S, Goda F, et al. Tissue Doppler echocardiography for predicting arterial stiffness assessed by cardio-ankle vascular index. Tohoku J Exp Med. 2009;217(2):139-146.
94. Noike H, Nakamura K, Sugiyama Y, et al. Changes in cardio-ankle vascular index in smoking cessation. J Atheroscler Thromb. 2010; 17(5):517-525.

95. Marti R, Parramon D, Garcia-Ortiz L, et al. Improving interMediAte risk management. MARK study. BMC Cardiovasc Disord. 2011;11:61.

Integrated Blood Pressure Control

Dovepress

\section{Publish your work in this journal}

Integrated Blood Pressure Control is an international, peer-reviewed open-access journal focusing on the integrated approach to managing hypertension and risk reduction. Treating the patient and comorbidities together with diet and lifestyle modification and optimizing healthcare resources through a multidisciplinary team approach constitute key

features of the journal. This journal is indexed on American Chemical Society's Chemical Abstracts Service (CAS). The manuscript management system is completely online and includes a very quick and fair peerreview system, which is all easy to use. Visit http://www.dovepress.com/ testimonials.php to read real quotes from published authors.

Submit your manuscript here: http://www.dovepress.com/integrated-blood-pressure-control-journal 